Check for updates

Cite this: Food Funct., 2017, 8, 2485

\title{
Ellagitannin-rich bioactive extracts of Tuberaria lignosa: insights into the radiation-induced effects in the recovery of high added-value compounds $\uparrow$
}

\author{
José Pinela, (DD a,b M. A. Prieto, ${ }^{a, c}$ Amilcar L. Antonio, ${ }^{a}$ Ana Maria Carvalho, ${ }^{a}$ \\ M. Beatriz P. P. Oliveira, ${ }^{b}$ Lillian Barros (D) a and Isabel C. F. R. Ferreira (D)*a
}

\begin{abstract}
Ellagitannins are polyphenols responsible for a number of bioactivities and health-promoting effects. These industrially important molecules can be affected by post-harvest treatments and recovery processes, but little is known about the irradiation-induced effects on their integrity, bioactivity and extractability. Herein, the impact of gamma radiation on the production of ellagitannin-rich extracts was investigated using Tuberaria lignosa as a case study. These effects were compared with those induced in flavonoids and organic acids. The extracts were particularly rich in hydrophilic antioxidants (measured by in vitro assays). The recovery of different phytochemicals was favoured by longer extraction times. Ellagitannins (mainly punicalagin derivatives) were extracted better from samples irradiated at 5 kGy and were not significantly affected by the $10 \mathrm{kGy}$ dose. However, the total contents of flavonoids and organic acids were decreased by the consequent increase in irradiation dose. Therefore, this study supports the use of gamma radiation for processing $T$. lignosa, aiming to obtain ellagitannin-rich bioactive extracts.
\end{abstract}

Received 31st March 2017 Accepted 1st June 2017

DOI: $10.1039 / \mathrm{c} 7 \mathrm{fo} 00500 \mathrm{~h}$

rsc.li/food-function lignosa (Sweet) Samp., Fam. Cistaceae). ${ }^{4}$ These water-soluble polyphenols contain ellagic and gallagic acids linked to a sugar moiety and are naturally found in the forms of two reversible $\alpha$ - and $\beta$-anomers. It has been shown that punicalagins inhibit oxidative stress, inflammatory responses and apoptosis, along with other beneficial effects. ${ }^{5-7}$ Therefore, the exploitation of ellagitannin (punicalagin)-rich natural sources is of high industrial interest.

Industrial preservation and decontamination processes are applied to prevent the growth of microorganisms on plant materials and to facilitate their storage and transportation. ${ }^{4,8,9}$ Conventional decontamination methods are not suitable for dried plant materials. Fumigation with chemical agents was used in the past for disinfestation of dried commodities during storage; but the use of these chemicals is now prohibited or increasingly restricted in several countries due to serious adverse effects on human health and environment. ${ }^{10}$ Heat treatments are not suitable, while ultraviolet radiation is not effective in decontaminating large volumes due to its low penetration capacity. ${ }^{11}$ Among the non-thermal and nonchemical methods, gamma radiation is by far the most effective technique to preserve the chemical and hygienic quality of plant commodities and reduce losses associated with microbial contamination and insect infestation. Despite a general bad feeling of consumers about food irradiation, the treatment is widely accepted by the food industry and is a safer alternative compared to chemical fumigants. ${ }^{12}$ The joint 
FAO/IAEA/WHO Experts Committee ensures that any food irradiated up to a maximum dose of $10 \mathrm{kGy}$ is safe and wholesome for human consumption. ${ }^{13}$

The gamma irradiation treatment is well established as a non-thermal processing method. However, an inadequate exposure to gamma rays might result in minimal availability of health-promoting compounds. The integrity of phytochemicals/antioxidants may be affected by the direct action of gamma rays or by interaction with radiolytic products (free radicals and radiation-induced degradation products). ${ }^{14,15}$ The chemical bonds of polyphenols can be broken, thereby releasing soluble low-molecular-weight phenols, leading to a variation in the amount of bioactive molecules. ${ }^{15,16}$ The levels of physical and chemical modifications might vary depending on the plant material under study, the sensitivity of the phytochemicals/antioxidants towards irradiation, irradiation dose delivered, and the type of radiation source employed. ${ }^{15,17-19}$ Consequently, irradiation may affect the extraction yield and, in some cases, improve the content (extractability) of polyphenols and the antioxidant properties of the obtained extracts. ${ }^{18-20}$ To evaluate the effects of ionizing radiation on the extraction/degradation of bioactive compounds from plant matrices, it is important to evaluate the extraction kinetics by monitoring the concentration changes over time using chromatographic and spectrometric techniques.

The content of phenolic compounds in infused and decocted extracts prepared from irradiated wild samples of T. lignosa was previously evaluated by Pinela et al. ${ }^{4}$ However, the impact of the irradiation treatment in the extraction/degradation kinetics of the different phytochemicals was not evaluated. This study was carried out to investigate the effects of gamma radiation on the production of ellagitannin-rich bioactive extracts from $T$. lignosa using response surface methodology (RSM) for analysis. These effects were compared with those induced in other compounds, namely in flavonoids and organic acids. In addition, the presence of hydrophilic and lipophilic antioxidants on the extracts was evaluated by distinct in vitro assays.

\section{Materials and methods}

\subsection{Plant material, standards and reagents}

Samples of T. lignosa, available as dried rosettes of leaves and inflorescences, were obtained from a local herbal shop in Bragança (North-eastern Portugal). Botanical identification of all plant materials used was previously confirmed. Amber Perspex routine dosimeters, Batch V, were purchased from Harwell Company (Oxfordshire, UK). Organic acids (oxalic, quinic, shikimic and succinic acids) and trolox (6-hydroxy2,5,7,8-tetramethylchroman-2-carboxylic acid) were purchased from Sigma (St. Louis, MO, USA). Acetonitrile (99.9\%, HPLC grade) was purchased from Fisher Scientific (Lisbon, Portugal). Formic acid was purchased from Prolabo (VWR International, France). The phenolic compound standards (apigenin-6- $C$-glucoside, $p$-coumaric acid, ellagic acid, gallic acid, kaempferol-3-O-glucoside, kaempferol-3-O-rutinoside, luteolin-6- $C$-glucoside, quercetin-3-O-glucoside and quercetin3-O-rutinoside) were purchased from Extrasynthese (Genay, France). 2,2-Diphenyl-1-picrylhydrazyl (DPPH) was obtained from Alfa Aesar (Ward Hill, MA, USA). All other chemicals and solvents were of analytical grade and purchased from common sources. Water was treated in a Milli-Q water purification system (Merck Millipore, model A10, Billerica, MA, USA).

\subsection{Irradiation of plant materials}

Plant samples were packaged in sterilized polyethylene bags and subjected to the predicted ionizing radiation doses of 5 and $10 \mathrm{kGy}$. A non-irradiated control (0 kGy) followed all the experiments. The irradiation process was performed in a cobalt-60 experimental chamber (Precisa 22, Graviner Manufacturing Company Ltd, UK) with four sources and a total activity of $177 \mathrm{TBq}(4.78 \mathrm{kCi})$, located at the Centre for Nuclear Sciences and Technologies (C2TN), Portugal. During the irradiation process, amber Perspex routine dosimeters were used to measure the distribution of the absorbed energy and to determine the maximum $\left(D_{\max }\right)$ and the minimum $\left(D_{\text {min }}\right)$ dose absorbed by the samples, following the procedure previously described by Fernandes et $a l^{21}$ The measured average doses were $4.85 \pm 0.47$ and $9.92 \pm 0.52 \mathrm{kGy}$ for the samples irradiated at the predicted doses 5 and $10 \mathrm{kGy}$, respectively. The estimated dose rate for the irradiation position, obtained with a Fricke dosimeter, was $1.9 \mathrm{kGy} \mathrm{h}^{-1}$ and the dose uniformity ratio $\left(D_{\max } / D_{\min }\right)$ was 1.1 .

\subsection{Extraction method}

The non-irradiated and irradiated plant materials were subjected to a solid-liquid extraction as defined in the $3^{2}$ full factorial design presented in Table 1 . Boiling water $(0.2 \mathrm{~L})$ was used as an extraction solvent since it is low-priced, easily available and non-toxic. After extraction, the obtained solutions were filtered through Whatman No. 4 paper and a portion was lyophilized (Free Zone 4.5, Labconco, Kansas City, MO, USA) for the subsequent chromatographic analysis of organic acids and phenolic compounds. The screening of antioxidants was performed on the obtained solutions. The extraction yield was expressed as percentage $(\%, \mathrm{w} / \mathrm{w})$.

\subsection{Screening of antioxidants}

The obtained solutions were redissolved in water (final concentration: $1 \mathrm{mg} \mathrm{mL}{ }^{-1}$ ) and further diluted to different concentrations in order to evaluate the antioxidant capacity in a dose-response format using in vitro assays based on hydrophilic and lipophilic reaction mechanisms. $^{22}$

\subsubsection{Hydrophilic antioxidants}

$D P P H$ free-radical scavenging activity. The solutions at different concentrations $(30 \mu \mathrm{L})$ were mixed with a methanolic solution $(270 \mu \mathrm{L})$ containing DPPH free-radicals $\left(6 \times 10^{-5} \mathrm{M}\right)$ in a 96-well plate. The reaction mixture was left to stand for $60 \mathrm{~min}$ in the dark. After that, the reduction of DPPH freeradicals was determined by measuring the absorbance at $515 \mathrm{~nm}$ in an ELX800 Microplate Reader (Bio-Tek Instruments, Inc., 


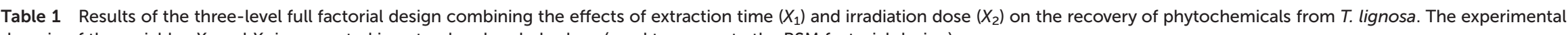
domain of the variables $X_{1}$ and $X_{2}$ is presented in natural and coded values (used to compute the RSM factorial design)

\begin{tabular}{|c|c|c|c|c|c|c|c|c|c|c|c|c|c|c|c|c|c|c|c|c|c|c|c|c|c|c|c|c|c|}
\hline \multicolumn{30}{|c|}{ Experimental design } \\
\hline Observations & & & 1 & 4 & 5 & 2 & 6 & 7 & 3 & 8 & 9 & 10 & 13 & 14 & 11 & 15 & 16 & 12 & 17 & 18 & 19 & 22 & 23 & 20 & 24 & 25 & 21 & 26 & 27 \\
\hline \multirow[t]{2}{*}{ Natural values } & $\left(X_{1}\right)$ : Time $(t)$ & $(\min )$ & 0 & 5 & 5 & 0 & 5 & 10 & 0 & 10 & 10 & 0 & 5 & 5 & 0 & 5 & 10 & 0 & 10 & 10 & 0 & 5 & 5 & 0 & 5 & 10 & 0 & 10 & 10 \\
\hline & $\left(X_{2}\right)$ : Dose $(D)$ & (kGy) & 0 & 0 & 5 & 5 & 10 & 0 & 10 & 5 & 10 & 0 & 0 & 5 & 5 & 10 & 0 & 10 & 5 & 10 & 0 & 0 & 5 & 5 & 10 & 0 & 10 & 5 & 10 \\
\hline \multirow[t]{2}{*}{ Coded values } & $\left(X_{1}\right)$ : Time $(t)$ & & -1 & 0 & 0 & -1 & 0 & 1 & -1 & 1 & 1 & -1 & 0 & 0 & -1 & 0 & 1 & -1 & 1 & 1 & -1 & 0 & 0 & -1 & 0 & 1 & -1 & 1 & 1 \\
\hline & $\left(X_{2}\right)$ : Dose $(D)$ & & -1 & -1 & 0 & 0 & 1 & -1 & 1 & 0 & 1 & -1 & -1 & 0 & 0 & 1 & -1 & 1 & 0 & 1 & -1 & -1 & 0 & 0 & 1 & -1 & 1 & 0 & 1 \\
\hline
\end{tabular}

\section{Responses for RSM application} Antioxidant $\quad \mathrm{DPPH}^{-}$

activity Scavenging

activity

activity

Reducing

power

$\beta$-Carotene

inhibition

inhibition

TBARS

Pormation

Organic acids Oxalic acid Quinic acid Shikimic acid Succinic acid Total

$\left(\mathrm{IC}_{50} \mathrm{mg}\right.$ per g P)

$\left(\mathrm{IC}_{50} \mathrm{mg}\right.$

per g P)

(IC $50 \mathrm{mg}$

per g P)

$\left(\mathrm{IC}_{50} \mathrm{mg}\right.$ per $g$ P)

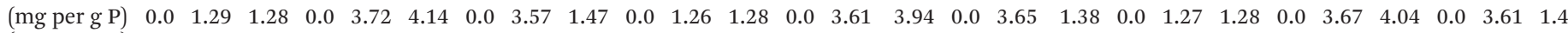

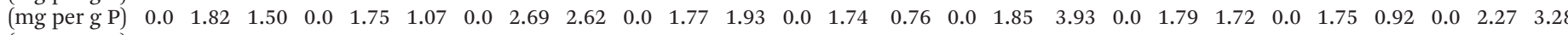

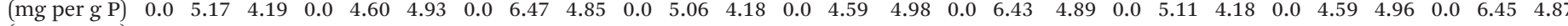
$\begin{array}{llllllllllllllllllllllllllll}(\mathrm{mg} \text { per g P) } & 0.0 & 0.0 & 0.0 & 0.0 & 0.0 & 10.9 & 0.0 & 5.61 & 3.56 & 0.0 & 0.0 & 0.0 & 0.0 & 0.0 & 9.92 & 0.0 & 5.64 & 3.55 & 0.0 & 0.0 & 0.0 & 0.0 & 0.0 & 10.4 & 0.0 & 5.62 & 3.55\end{array}$ $\begin{array}{llllllllllllllllllllllllllll}(\mathrm{mg} \text { per g P) } & 0.0 & 8.28 & 6.96 & 0.0 & 10.1 & 21.1 & 0.0 & 18.3 & 12.4 & 0.0 & 8.09 & 7.39 & 0.0 & 9.95 & 19.6 & 0.0 & 17.5 & 13.7 & 0.0 & 8.18 & 7.18 & 0.0 & 10.1 & 20.3 & 0.0 & 17.9 & 13.13\end{array}$

Ellagitannin Punicalin ${ }^{a}$ Punicalagin $(\text { isomer } 1)^{a}$ (isomer 1) Punicalag gallate

(isomer 1$)^{a}$ Punicalagin (isomer 2) Punicalagin gallate (isomer 2) $^{a}$ Total

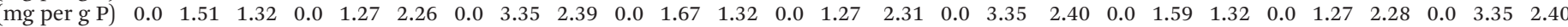

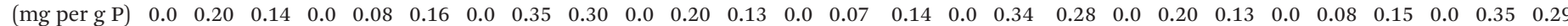

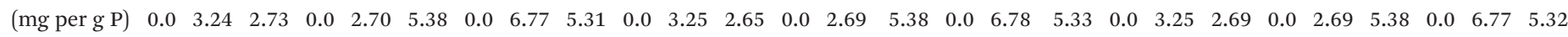

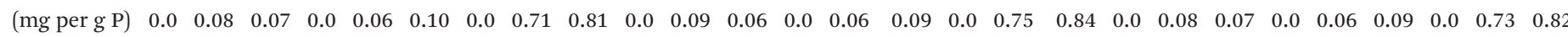

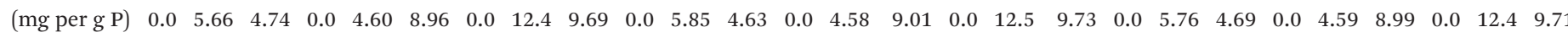




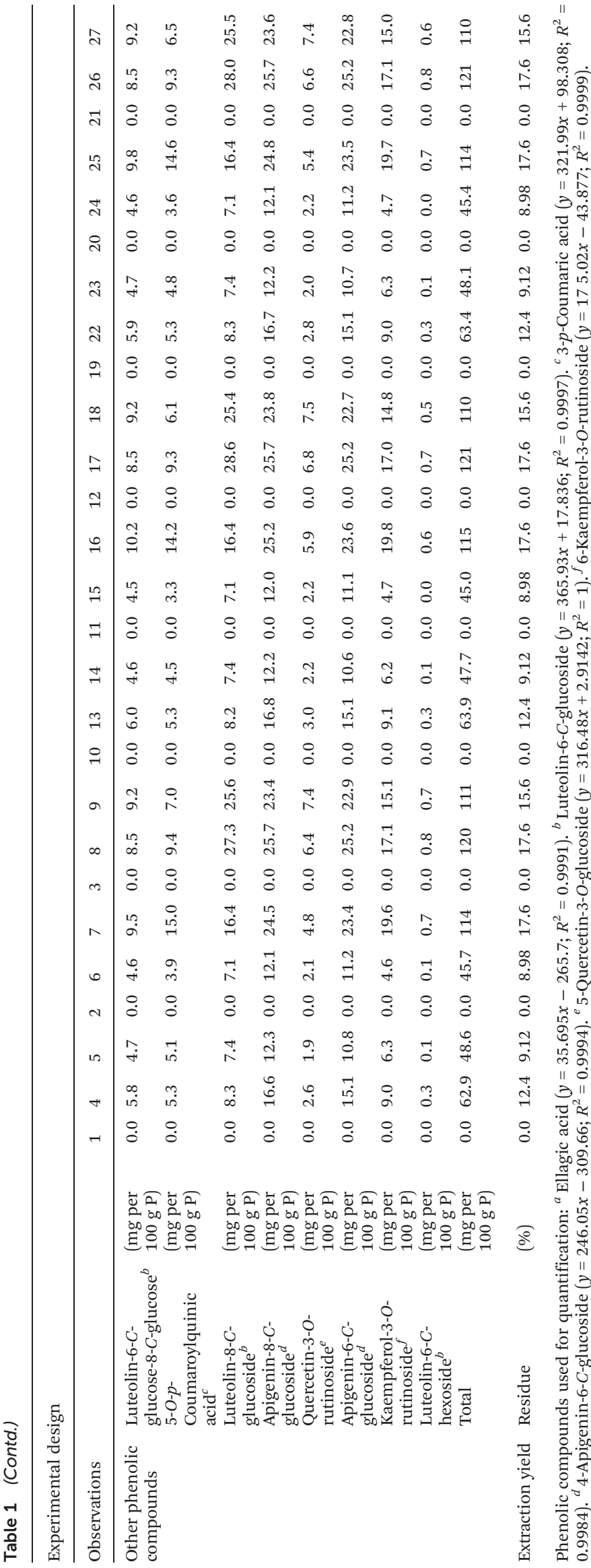

Winooski, VT, USA). For each sample, the measured absorbance was transformed in terms of the remaining $\mathrm{nM}$ of DPPH radicals.

Reducing power. The reducing power assay is used to evaluate the capacity of the extracts to convert potassium ferricyanide $\left(\mathrm{Fe}^{3+}\right)$ into potassium ferrocyanide $\left(\mathrm{Fe}^{2+}\right)$, which reacts with ferric chloride to form a ferric-ferrous complex that can be monitored spectrophotometrically. The solutions at different concentrations $(0.5 \mathrm{~mL})$ were mixed with sodium phosphate buffer (200 mM, pH 6.6, $0.5 \mathrm{~mL}$ ) and potassium ferricyanide $(1 \% \mathrm{w} / \mathrm{v}, 0.5 \mathrm{~mL})$. The mixture was incubated at $50{ }^{\circ} \mathrm{C}$ for $20 \mathrm{~min}$, and then trichloroacetic acid $(10 \% \mathrm{w} / \mathrm{v}, 0.5 \mathrm{~mL})$ was added. The mixture $(0.8 \mathrm{~mL})$ was poured into a 48 -well plate containing deionised water $(0.8 \mathrm{~mL})$ and ferric chloride $(0.1 \%$ $\mathrm{w} / \mathrm{v}, 0.16 \mathrm{~mL}$ ), and the absorbance was measured at $690 \mathrm{~nm}$ using the microplate reader described above. For each sample, the measured absorbance was transformed in terms of nM of reduced $\mathrm{Fe}^{2+}$.

\subsubsection{Lipophilic antioxidants}

Thiobarbituric acid reactive substances (TBARS) formation inhibition capacity. The solutions at different concentrations $(0.2 \mathrm{~mL})$ were incubated with a brain tissue homogenate $(0.1 \mathrm{~mL})$; prepared according to Pinela et $a{ }^{4}{ }^{4}$ in the presence of $\mathrm{FeSO}_{4}(10 \mu \mathrm{M} ; 0.1 \mathrm{~mL})$ and ascorbic acid $(0.1 \mathrm{mM} ; 0.1 \mathrm{~mL})$ at $37{ }^{\circ} \mathrm{C}$ for $1 \mathrm{~h}$. The reaction was stopped by the addition of trichloroacetic acid $(28 \% \mathrm{w} / \mathrm{v}, 0.5 \mathrm{~mL})$, followed by thiobarbituric acid (TBA, $2 \%, \mathrm{w} / \mathrm{v}, 0.38 \mathrm{~mL}$ ). The mixture was then heated at $80{ }^{\circ} \mathrm{C}$ for $20 \mathrm{~min}$. After centrifugation at $3000 \mathrm{~g}$ for $10 \mathrm{~min}$ to remove the precipitated protein, the colour intensity of the malondialdehyde (MDA)-TBA complex in the supernatant was measured by its absorbance at $532 \mathrm{~nm}$. The measured absorbance was transformed in terms of inhibition ratio (IR, \%), which was calculated using the following expression:

$$
\operatorname{IR}(\%)=[(C-S) / C] \times 100,
$$

where $C$ and $S$ are the absorbance of the control and extract solution, respectively.

$\beta$-Carotene beaching inhibition capacity. A solution of $\beta$-carotene was prepared by dissolving $\beta$-carotene $(2 \mathrm{mg})$ in chloroform $(10 \mathrm{~mL})$. Two millilitres of this solution were pipetted into a round-bottom flask and the chloroform was removed at $40{ }^{\circ} \mathrm{C}$ under vacuum. Then, linoleic acid (40 mg), tween 80 emulsifier (400 mg) and distilled water $(100 \mathrm{~mL})$ were added and vigorously shaken. The solutions at different concentrations $(0.2 \mathrm{~mL})$ were shaken with the prepared emulsion (4.8 $\mathrm{mL})$ and the zero time absorbance was measured at $470 \mathrm{~nm}$. After $2 \mathrm{~h}$ of incubation at $50^{\circ} \mathrm{C}$, the absorbance of the mixture was measured again. The $\beta$-carotene bleaching inhibition as a function of the remaining $\beta$-carotene $(\mathrm{R} \beta, \%)$ after $120 \mathrm{~min}$ of interaction was calculated using the following expression:
$\mathrm{R} \beta(\%)=\left(\beta_{120} / \beta_{0}\right) \times 100$, 
where $\beta_{0}$ and $\beta_{120}$ are the remaining equivalent quantities of $\beta$-carotene at the start $(t=0)$ and after $120 \mathrm{~min}$ of the oxidation process, respectively.

2.4.3. Quantification of the antioxidant activity through dose-response analysis. Each sample obtained under the experimental design presented in Table 1 was studied in a dose-response format. Among all the different standardized formats for presenting the results of the hydrophilic and lipophilic antioxidant determinations, the Weibull cumulative distribution function ${ }^{23}$ was selected to computed the doseresponse of each sample as discussed in other studies. ${ }^{24}$ Thus, the variation of each antioxidant response $(A)$ as a function of increasing concentration of an antioxidant extract $(E)$ can be satisfactorily described using the Weibull model rearranged for our own purposes as follows:

$$
R(E)=K\left\{1-\exp \left[-\ln (2)\left(E / \mathrm{IC}_{50}\right)^{a}\right]\right\}
$$

The parameter $K$ is the maximum asymptotic value of the response, the parameter $a$ is a shape parameter related to the slope that can produce potential profiles $(a<1)$, first order kinetic ones $(a=1)$ and a variety of sigmoidal profiles $(a>1)$, and the $\mathrm{IC}_{50}$ is the concentration needed to reach $50 \%$ of maximum response. The results are expressed in $\mathrm{IC}_{50}$ values (mg per g P).

\subsection{Analysis of organic acids}

Organic acids were determined following the procedures previously described by Pereira et $a l^{25}$ and optimized by Barros et $a{ }^{26}{ }^{26}$ The lyophilized extracts $(\sim 10 \mathrm{mg})$ were dissolved in $1 \mathrm{~mL}$ of meta-phosphoric acid and filtered through $0.2 \mu \mathrm{m}$ nylon filters. The analysis was performed using a Shimadzu 20A series UFLC (Shimadzu Corporation, Kyoto, Japan). Separation was achieved on a Sphereclone (Phenomenex, Torrance, CA, USA) reverse phase $\mathrm{C}_{18}$ column $(5 \mu \mathrm{m}, 250 \times$ $4.6 \mathrm{~mm}$ i.d.) thermostated at $35{ }^{\circ} \mathrm{C}$. The elution was performed with sulphuric acid $(3.6 \mathrm{mM})$ using a flow rate of $0.8 \mathrm{~mL} \mathrm{~min}^{-1}$. Detection was carried out in a photodiode array detector (PDA) at $215 \mathrm{~nm}$. The organic acids found were quantified by comparison of the area of their peaks with calibration curves obtained from commercial standards. The results are expressed in $\mathrm{mg}$ per $\mathrm{g}$ of plant material (mg per g P).

\subsection{Analysis of phenolic compounds}

The lyophilized extracts $(\sim 10 \mathrm{mg})$ were dissolved in water and filtered through $0.22 \mu \mathrm{m}$ disposable LC filter disks. Chromatographic analysis was performed using a Dionex Ultimate 3000 UPLC (Thermo Scientific, San Jose, CA, USA) system equipped with a diode array detector coupled to a electrospray ionization mass detector (ThermoFinnigan, San Jose, CA, USA). The chromatographic system and analytical procedures were previously described by Bessada et al. ${ }^{27}$ The phenolic compounds were identified using $280 \mathrm{~nm}$ and $370 \mathrm{~nm}$ as preferred wavelengths and by comparing their retention times and UV-vis and mass spectra with those obtained from auth- entic standards, when available. For quantitative analysis, calibration curves were prepared by injection of known concentrations of different standard compounds. The results are expressed in $\mathrm{mg}$ per $\mathrm{g}$ of plant material ( $\mathrm{mg}$ per $\mathrm{g} \mathrm{P}$ ) for the major compounds (ellagitannin derivatives) and in $\mathrm{mg}$ per $100 \mathrm{~g}$ of plant material (mg per $100 \mathrm{~g} \mathrm{P}$ ) for the minor ones (other phenolic compounds).

\subsection{Response surface methodology}

The RSM was applied to analyse the impact of the ionizing radiation treatment in the extraction or degradation kinetics of different phytochemicals from $T$. lignosa aerial parts. This statistical tool allows modelling processes in which a response of interest is affected by different independent variables (in this case $t$ and $D$ ) and accessing possible interactions using a reduced number of experimental trials.

2.7.1 Experimental design. The combined effects of the variables' extraction time $(t)$ and irradiation dose $(D)$ were tested under a full factorial design involving the combination of three values for each factor (minimum, mean and maximum) and three replicates per condition. The number of experiments $n$ for $k$ factors is given as $n=3^{k}$. Experimental runs were randomized to minimize the effects of unexpected variability in the observed responses. The variables were coded according to the following equation:

$$
X=\left(x_{\mathrm{a}}-x_{0}\right) / \Delta x,
$$

where $X$ is the coded value for the variables $t$ and $D, x_{\mathrm{a}}$ is the corresponding actual value, $x_{0}$ is the actual value in the centre of the domain, and $\Delta x$ is the increment of $x_{\mathrm{a}}$ corresponding to a variation of 1 unit of $X$. The natural and coded values are presented in Table 1.

2.7.2. Mathematical model. The response surface model was fitted by means of least-squares calculation using the following Box-Behnken design equation:

$$
Y=b_{0}+\sum_{i=1}^{n} b_{i} X_{i}+\sum_{\substack{i=1 \\ j>i}}^{n-1} \sum_{j=2}^{n} b_{i j} X_{i} X_{j}+\sum_{i=1}^{n} b_{i i} X_{i}^{2},
$$

where $Y$ is the dependent variable (response variable) to be modelled, $X_{i}$ and $X_{j}$ define the independent variables, $b_{0}$ is the constant coefficient, $b_{i}$ is the coefficient of linear effect, $b_{i j}$ is the coefficient of interaction effect, $b_{i i}$ is the coefficients of quadratic effects and $n$ is the number of variables.

\subsection{Numerical methods and statistical analysis}

All fitting procedures, coefficient estimates and statistical calculations were performed using a Microsoft Excel spreadsheet. The model fitting and statistical analysis of the experimental results according to the proposed equations were carried out in four phases:

Coefficient determination: Parametric estimates were obtained by the minimization of the sum of quadratic differences between observed and model-predicted values using the 
nonlinear least-square (quasi-Newton) method provided by the macro Solver in Microsoft Excel $2003^{28}$ which allows a quick testing of a hypotheses and its consequences. ${ }^{29}$

Coefficient significance: The determination of the parametric confidence intervals was done using the "SolverAid". ${ }^{30}$ The model was simplified by dropping the terms that were not statistically significant for a $p$-value $>0.05$.

Model consistency: The Fisher F-test $(\alpha=0.05)$ was used to determine whether the constructed models were adequate to describe the observed data. ${ }^{31}$

Other statistical assessment criteria: To recheck the uniformity of the model the following criteria were applied: (a) the "SolverStat" macro was used for the assessment of parameter and model prediction uncertainties; ${ }^{32}$ (b) the $R^{2}$ was interpreted as the proportion of variability of the dependent variable explained by the model; (c) the adjusted coefficient of determination $\left(R^{2}\right.$ adj $)$ was a correction to $R^{2}$ taking into account the number of variables used in the model; (d) bias and accuracy factors of all equations were calculated to evaluate the quality of the fitting to the experimental data such as the mean squared error (MSE), the root mean square error (RMSE) and the mean absolute percentage error (MAPE); (e) the Durbin-Watson (DW) coefficient was used to check if the residuals of the model were not autocorrelated; and (f) the analysis of variance (ANOVA) table was used to evaluate the explanatory power of each variable.

\section{Results and discussion}

\subsection{Response criteria for RSM analysis}

3.1.1 Extraction yield. Extraction yields ranging from 8.98 to $17.6 \%$ were obtained when the plant materials irradiated at 10 and $5 \mathrm{kGy}$ were extracted for 5 and $10 \mathrm{~min}$ respectively (Table 1). Slightly higher yields (19.7-21.2) were obtained by Pinela et $a{ }^{4}{ }^{4}$ when $T$. lignosa samples were prepared by decoction (method in which the dried plant is boiled for $5 \mathrm{~min}$ and the mixture is then left to stand at $25{ }^{\circ} \mathrm{C}$ for $5 \mathrm{~min}$ more). Based on the amount of extracted residue the results were analyzed in terms of plant materials (Table 2) and extracted residues (Table S1 $\dagger$ ). The last form of expressing the results was selected for the detailed discussion. However, the fitting coefficients obtained after applying the Box-Behnken model and the statistical information of the fitting analysis are similar for both cases.

3.1.2. Hydrophilic and lipophilic antioxidants. Antioxidants may act in various ways by scavenging free radicals by chelating metal ions and by decomposing peroxides. ${ }^{33}$ Therefore the presence of hydrophilic and lipophilic antioxidant compounds in the different extracts was evaluated using distinct in vitro assays with known reaction mechanisms. The results of the screening of antioxidants are presented in Table 1 . The hydrophilic responses were measured via DPPH free-radical scavenging activity and reducing power while the $\beta$-carotene bleaching inhibition and TBARS formation inhibition assays were used to evaluate the lipophilic ones. The results were expressed in $\mathrm{IC}_{50}$ values (mg per $\mathrm{g}$ P) corresponding to the concentration of plant material (or extract) needed to reach $50 \%$ of the maximum response. Thus, the lower the $\mathrm{IC}_{50}$ value the higher the antioxidant activity. As shown in Table 2 no statistically significant results were found for the lipophilic antioxidant responses $\left(R^{2} \leq 0.54\right)$. This demonstrates that hydrophilic antioxidants were predominant in the extracts which was somewhat expected as the extraction solvent was water. To accurately assess the effects of the different gamma irradiation doses on the lipophilic fraction of antioxidants the use of apolar extraction solvents would be required. Additionally the measured antioxidant responses may be attributed to the phenolic fraction constituted by ellagitannin polyphenols with several hydroxyl functional groups in ortho positions in their structures which could provide hydrogen atoms and support the unpaired electron. ${ }^{3}$

3.1.3. Organic acids and phenolic compounds. The results of the organic acids and phenolic compounds analysis are presented in Table 1. Shikimic acid was the most abundant organic acid in T. lignosa. Oxalic quinic and succinic acids were also quantified. Ellagitannin derivatives namely punicalin punicalagin isomers and punicalagin gallate isomers were found to be the predominant phenolic compounds representing approximately $90 \%$ of the total phenolic fraction. Among them punicalagin (isomer 2) was the most abundant. A phenolic acid (5-O- $p$-coumaroylquinic acid), flavones (luteolin-6- $C$-glucose-8- $C$-glucose luteolin-8- $C$-glucoside and luteolin-6- $C$-hexoside) and flavonols (apigenin-8- $C$ glucoside apigenin-6- $C$-glucoside quercetin-3-O-rutinoside and kaempferol-3-O-rutinoside) were also identified in the studied plant material. The presented phenolic profile (shown in Fig. 1) is similar to that previously characterized by our research team in commercial samples of this species. ${ }^{4}$ All quantified phytochemicals were grouped in organic acid ellagitannin derivatives and other phenolics and the quantification values were used as dependent variables in the RSM analysis.

\subsection{Modelling and fitting the model}

The RSM experiment was designed based on the responses discussed above. The multivariable characterization performed by the RSM technique allows a simultaneous analysis of variables, reduces the number of coefficients used to describe the responses, provides better estimations of parameters, reduces the interval of confidence of the coefficients and minimizes the effects of experimental errors. This simultaneous description of all curves is very efficient when the experimental results obtained do not span the full range and some of them fail to provide information about one or more of the parameters of the equation. In addition standardizing the response optimal data analysis is performed independently of the experimental values of the variables which is one of the common issues when analysing several factors. ${ }^{34,35}$

The variables $t$ and $D$ notably altered the efficiency of the extraction process. A full factorial RSM design of three 


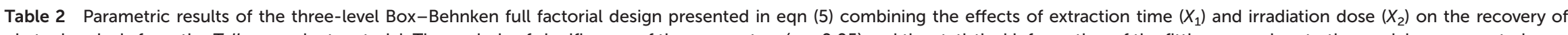
phytochemicals from the $T$. lignosa plant material. The analysis of significance of the parameters $(\alpha=0.05)$ and the statistical information of the fitting procedure to the model are presented

\begin{tabular}{|c|c|c|c|c|c|c|c|c|c|c|c|c|c|c|}
\hline & & \multicolumn{6}{|c|}{ Fitting coefficients obtained after applying the Box-Behnken model } & \multicolumn{7}{|c|}{ Statistical information of the fitting analysis } \\
\hline & & \multirow{2}{*}{$\begin{array}{l}\text { Intercept } \\
b_{0}\end{array}$} & \multicolumn{2}{|l|}{ Linear effect } & \multicolumn{2}{|l|}{ Quadratic effect } & \multirow{2}{*}{$\begin{array}{l}\text { Interactive effect } \\
b_{12}(t \times D)\end{array}$} & \multirow{2}{*}{ Obs } & \multirow[b]{2}{*}{$R^{2}$} & \multirow[b]{2}{*}{$R_{\text {adj }}^{2}$} & \multirow[b]{2}{*}{ MSE } & \multirow[b]{2}{*}{ RMSE } & \multirow[b]{2}{*}{ MAPE } & \multirow[b]{2}{*}{ DW } \\
\hline & & & $b_{1}(t)$ & $b_{2}(D)$ & $b_{11}\left(t^{2}\right)$ & $b_{22}\left(D^{2}\right)$ & & & & & & & & \\
\hline Extraction yield & Residue & $10.17 \pm 0.56$ & $8.49 \pm 0.39$ & $-0.89 \pm 0.39$ & $-1.69 \pm 0.68$ & ns & $-0.48 \pm 0.27$ & 27 & 0.9902 & 0.988 & 64.1 & 8.2 & 5.6 & 2.3 \\
\hline \multirow[t]{4}{*}{ Antioxidant activity } & $\begin{array}{l}\text { DPPH }^{*} \text { scavenging } \\
\text { activity }\end{array}$ & $339.1 \pm 19.9$ & $101.1 \pm 14.1$ & $25.9 \pm 14.1$ & $-238.0 \pm 24.4$ & ns & ns & 27 & 0.9678 & 0.961 & 26370 & 162 & 8.9 & 1.3 \\
\hline & Reducing power & $268.5 \pm 19.1$ & $73.4 \pm 13.5$ & $15.7 \pm 13.5$ & $-195.2 \pm 23.3$ & ns & ns & 27 & 0.9528 & 0.944 & 16486 & 128 & 10.7 & 1.3 \\
\hline & $\begin{array}{l}\beta \text {-Carotene } \\
\text { bleaching inhibition }\end{array}$ & $317.9 \pm 105.7$ & $102.3 \pm 74.8$ & ns & $-215.6 \pm 129.5$ & ns & ns & 27 & 0.4678 & 0.408 & 47560 & 218 & 42.4 & 2.5 \\
\hline & $\begin{array}{l}\text { TBARS formation } \\
\text { inhibition }\end{array}$ & $66.5 \pm 20.3$ & $18.8 \pm 14.4$ & $\mathrm{~ns}$ & $-47.6 \pm 24.9$ & ns & ns & 27 & 0.5053 & 0.462 & 1885 & 43 & 102 & 2.7 \\
\hline \multirow[t]{5}{*}{ Organic acids } & Oxalic acid & $1.70 \pm 0.36$ & $1.51 \pm 0.44$ & ns & ns & ns & $-0.65 \pm 0.54$ & 27 & 0.6988 & 0.664 & 3.2 & 1.8 & 43.3 & 2.0 \\
\hline & Quinic acid & $1.75 \pm 0.25$ & $1.08 \pm 0.18$ & $0.39 \pm 0.18$ & $-0.67 \pm 0.31$ & ns & $0.59 \pm 0.22$ & 27 & 0.9121 & 0.891 & 1.6 & 1.3 & 19.1 & 2.0 \\
\hline & Shikimic acid & $4.63 \pm 0.34$ & $2.71 \pm 0.24$ & ns & $-1.92 \pm 0.42$ & ns & ns & 27 & 0.9625 & 0.959 & 7.6 & 2.8 & 9.6 & 3.3 \\
\hline & Succinic acid & $1.76 \pm 0.17$ & $3.26 \pm 0.42$ & $-1.14 \pm 0.42$ & $1.51 \pm 0.71$ & ns & $-1.71 \pm 0.51$ & 27 & 0.8986 & 0.845 & 15.7 & 4.0 & 8.9 & 1.5 \\
\hline & Total & $8.53 \pm 0.54$ & $8.57 \pm 0.66$ & $-0.89 \pm 0.66$ & ns & ns & $-1.80 \pm 0.81$ & 27 & 0.9703 & 0.964 & 67.4 & 8.2 & 12.3 & 2.0 \\
\hline \multirow[t]{6}{*}{ Ellagitannin derivatives } & Punicalin & $0.58 \pm 0.06$ & $0.54 \pm 0.04$ & $-0.06 \pm 0.04$ & ns & $-0.06 \pm 0.03$ & $-0.05 \pm 0.05$ & 27 & 0.9734 & 0.937 & 0.53 & 0.73 & 20.90 & 2.1 \\
\hline & $\begin{array}{l}\text { Punicalagin } \\
\text { (isomer 1) }\end{array}$ & $1.56 \pm 0.25$ & $1.34 \pm 0.14$ & $\mathrm{~ns}$ & ns & $-0.30 \pm 0.14$ & ns & 27 & 0.9500 & 0.930 & 1.63 & 1.28 & 12.89 & 3.0 \\
\hline & $\begin{array}{l}\text { Punicalagin gallate } \\
\text { (isomer 1) }\end{array}$ & $0.16 \pm 0.04$ & $0.13 \pm 0.03$ & ns & ns & $-0.04 \pm 0.04$ & $0.04 \pm 0.03$ & 27 & 0.8449 & 0.795 & 0.02 & 0.14 & 43.09 & 1.6 \\
\hline & $\begin{array}{l}\text { Punicalagin } \\
\text { (isomer 2) }\end{array}$ & $3.15 \pm 0.27$ & $2.91 \pm 0.19$ & ns & ns & $-0.38 \pm 0.34$ & ns & 27 & 0.9757 & 0.950 & 7.71 & 2.78 & 12.33 & 2.5 \\
\hline & $\begin{array}{l}\text { Punicalagin gallate } \\
\text { (isomer 2) }\end{array}$ & $0.07 \pm 0.01$ & $0.27 \pm 0.06$ & $0.12 \pm 0.06$ & $0.20 \pm 0.10$ & ns & $0.18 \pm 0.07$ & 27 & 0.8844 & 0.760 & 0.02 & 0.14 & 75 & 1.7 \\
\hline & Total & $5.71 \pm 0.81$ & $5.19 \pm 0.44$ & ns & ns & $-0.87 \pm 0.04$ & ns & 27 & 0.9641 & 0.947 & 26.2 & 5.1 & 13.6 & 2.2 \\
\hline \multirow[t]{9}{*}{ Other phenolic compounds } & $\begin{array}{l}\text { Luteolin-6- } C \text { - } \\
\text { glucose-8- } C \text {-glucose }\end{array}$ & $4.71 \pm 0.31$ & $4.59 \pm 0.17$ & $-0.33 \pm 0.17$ & $-0.47 \pm 0.29$ & $0.52 \pm 0.29$ & ns & 27 & 0.9931 & 0.992 & 18.41 & 4.29 & 4.0 & 2.7 \\
\hline & $\begin{array}{l}5-O-p- \\
\text { Coumaroylquinic } \\
\text { acid }\end{array}$ & $4.91 \pm 0.28$ & $5.08 \pm 0.35$ & $-1.63 \pm 0.35$ & ns & ns & $-2.02 \pm 0.42$ & 27 & 0.9799 & 0.980 & 27.30 & 5.23 & 9.8 & 1.7 \\
\hline & $\begin{array}{l}\text { Luteolin- } \\
\text { 8-C-glucoside }\end{array}$ & $9.07 \pm 1.97$ & $11.65 \pm 1.08$ & $1.31 \pm 1.08$ & $4.07 \pm 1.87$ & $-2.24 \pm 1.87$ & $2.27 \pm 1.32$ & 27 & 0.9631 & 0.954 & 131.8 & 11.5 & 16.8 & 2.5 \\
\hline & $\begin{array}{l}\text { Apigenin- } \\
\text { 8-C-glucoside }\end{array}$ & $13.66 \pm 0.80$ & $12.36 \pm 0.57$ & $-0.98 \pm 0.57$ & $-1.30 \pm 0.99$ & ns & ns & 27 & 0.9889 & 0.987 & 133.7 & 11.6 & 6.4 & 2.2 \\
\hline & $\begin{array}{l}\text { Quercetin- } \\
\text { 3-O-rutinoside }\end{array}$ & $2.33 \pm 0.30$ & $3.23 \pm 0.21$ & $0.24 \pm 0.21$ & $0.90 \pm 0.36$ & ns & $0.52 \pm 0.26$ & 27 & 0.9798 & 0.975 & 9.58 & 3.09 & 11.9 & 1.5 \\
\hline & $\begin{array}{l}\text { Apigenin- } \\
6-C \text {-glucoside }\end{array}$ & $12.05 \pm 0.48$ & $11.92 \pm 0.59$ & $-0.78 \pm 0.59$ & ns & ns & ns & 27 & 0.9865 & 0.984 & 123.9 & 11.1 & 7.2 & 2.5 \\
\hline & $\begin{array}{l}\text { Kaempferol- } \\
\text { 3-O-rutinoside }\end{array}$ & $6.64 \pm 0.33$ & $8.62 \pm 0.23$ & $-1.51 \pm 0.23$ & $1.98 \pm 0.40$ & ns & $-1.18 \pm 0.28$ & 27 & 0.9966 & 0.996 & 67.8 & 8.23 & 4.7 & 1.6 \\
\hline & $\begin{array}{l}\text { Luteolin- } \\
\text { 6-C-hexoside }\end{array}$ & $0.15 \pm 0.05$ & $0.34 \pm 0.04$ & $-0.05 \pm 0.04$ & $0.19 \pm 0.06$ & ns & ns & 27 & 0.9459 & 0.935 & 0.12 & 0.34 & 47.9 & 2.0 \\
\hline & Total & $52.30 \pm 3.19$ & $57.79 \pm 2.25$ & $-3.72 \pm 2.25$ & $5.49 \pm 3.90$ & ns & ns & 27 & 0.9920 & 0.990 & 2906 & 53.9 & 6.2 & 2.1 \\
\hline
\end{tabular}

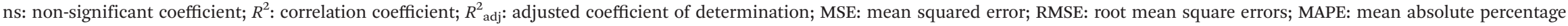
error; and DW: Durbin-Watson statistics. 


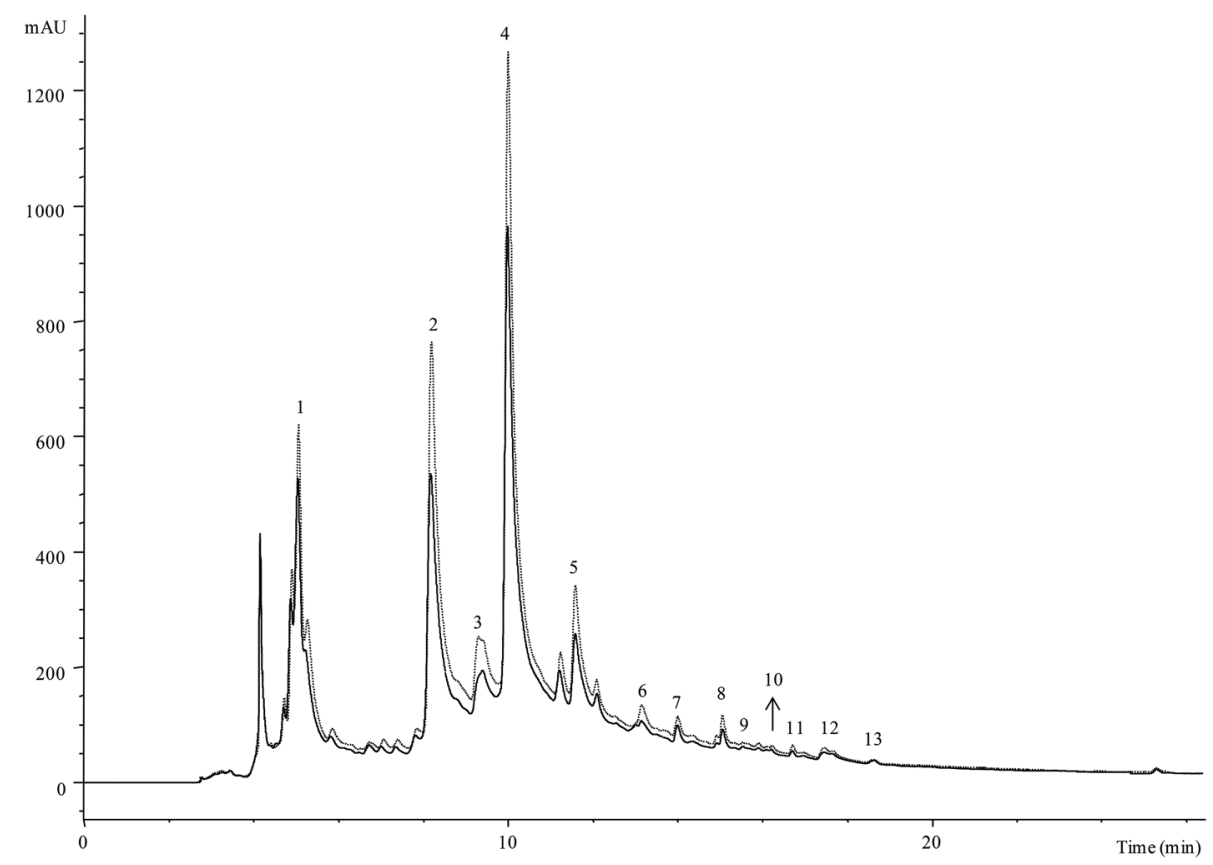

Fig. 1 HPLC profile of phenolic compounds in T. lignosa extracts obtained from non-irradiated (0 kGy; -) and irradiated (5 kGy; ---) samples processed for $10 \mathrm{~min}$ recorded at $280 \mathrm{~nm}$. (1): Punicalin; (2): punicalagin (isomer 1); (3): punicalagin gallate (isomer 1); (4): punicalagin (isomer 2); (5): punicalagin gallate (isomer 2); (6): luteolin-6-C-glucose-8-C-glucose; (7): 5-O- $p$-coumaroylquinic acid; (8): luteolin-8-C-glucoside; (9): apigenin8-C-glucoside; (10): quercetin-3-O-rutinoside; (11): apigenin-6-C-glucoside; (12): kaempferol-3-O-rutinoside; (13): luteolin-6-C-hexoside.

levels was applied and the second-order polynomial model of eqn (5) with interactive terms was used to predict each response. The experimental results obtained after running 27 trials (9 genuine combination conditions and 3 replicates per condition) for each response are presented in Table 1.

3.2.1. Theoretical response surface model. Table 2 shows for each response the estimated coefficient values of eqn (5) obtained by non-linear least-squares analysis, the coefficient parametric intervals and several numerical statistical criteria used to test the validity of the fitting procedure. The coefficients that showed effects with $p$-values higher than 0.05 were considered not significant (ns) at the $95 \%$ confidence level and were discarded for the model development. Therefore mathematical models were built according to the second-order polynomial model of eqn (5) obtaining the expressions described below.

When the response of the extracted residue (\%) was considered:

Residue:

$$
Y=10.17+8.49 t-0.89 D-1.69 t^{2}-0.48 t D
$$

When the antioxidant responses $\left(\mathrm{IC}_{50}\right.$ values $\mathrm{mg}$ per $\mathrm{g} \mathrm{P}$ ) were considered:

$\mathrm{DPPH}^{*}$ scavenging activity:

$$
Y=339.1+101.1 t+25.9 D-238.1 t^{2}
$$

Reducing power:

$$
Y=268.5+73.4 t+15.7 D-195.2 t^{2}
$$

$\beta$-Carotene bleaching inhibition:

$$
Y=317.9+102.3 t-215.6 t^{2}
$$

TBARS formation inhibition:

$$
Y=66.5+18.8 t-47.6 t^{2}
$$

When the response of organic acids ( $\mathrm{mg}$ per $\mathrm{g}$ P) was considered:

Oxalic acid:

$$
Y=1.70+1.51 t-0.65 t D
$$

Quinic acid:

$$
Y=1.75+1.08 t+0.39 D-0.67 t^{2}+0.59 t D
$$

Shikimic acid:

$$
Y=4.63+2.71 t-1.92 t^{2}
$$

Succinic acid:

$$
Y=1.76+3.26 t-1.44 D+1.51 t^{2}-1.71 t D
$$

Total:

$$
Y=8.53+8.57 t-0.89 D-1.80 t D
$$

When the response of ellagitannin derivatives ( $\mathrm{mg}$ per $\mathrm{g} \mathrm{P}$ ) was considered:

Punicalin:

$$
Y=0.58+0.54 t-0.06 D-0.06 D^{2}-0.05 t D
$$


Punicalagin (isomer 1):

$$
Y=1.56+1.34 t-0.30 D^{2}
$$

Punicalagin gallate (isomer 1):

$$
Y=0.16+0.13 t-0.04 D^{2}+0.04 t D
$$

Punicalagin (isomer 2):

$$
Y=3.15+2.91 t-0.38 D^{2}
$$

Punicalagin gallate (isomer 2):

$$
Y=0.07+0.27 t+0.12 D+0.20 t^{2}+0.18 t D
$$

Total:

$$
Y=5.71+5.19 t-0.87 D^{2}
$$

When the response of other phenolic compounds (mg per $100 \mathrm{~g}$ P) was considered:

Luteolin-6- $C$-glucose-8- $C$-glucose:

$$
Y=4.71+4.59 t-0.33 D-0.47 t^{2}+0.52 D^{2}
$$

5-O-p-Coumaroylquinic acid:

$$
Y=4.91+5.08 t-1.63 D-2.02 t D
$$

Luteolin-8- $C$-glucoside:

$$
\mathrm{Y}=9.07+11.65 t+1.31 D+4.07 t^{2}-2.24 D^{2}+2.27 t D
$$

Apigenin-8- $C$-glucoside:

$$
Y=13.66+12.36 t-0.98 D-1.30 t^{2}
$$

Quercetin-3-O-rutinoside:

$$
Y=2.33+3.23 t+0.24 D+0.90 t^{2}+0.52 t D
$$

Apigenin-6- $C$-glucoside:

$$
Y=12.05+11.92 t-0.78 D
$$

Kaempferol-3-O-rutinoside:

$$
Y=6.64+8.62 t-1.51 D+1.98 t^{2}-1.18 t D
$$

Luteolin-6- $C$-hexoside:

$$
Y=0.15+0.34 t-0.05 D+0.19 t^{2}
$$

Total:

$$
\mathrm{Y}=52.30+57.79 t-3.72 D+5.49 t^{2}
$$

In all cases, $t$ corresponds to extraction time, $D$ corresponds to the irradiation dose and $Y$ is the response. Only the significant parameters of the second-order polynomial model of eqn (5) were used since some terms were non-significant (Table 2). Although the obtained model coefficients are empirical and cannot be associated with physical or chemical significance their numerical values can be used for direct comparisons because they are presented based on the coded values of the variables in the experimental plan. In addition the model is useful for many operational purposes such as predicting results of untested operating conditions. The sign of the effect marks the performance of the response. In this way when a factor has a positive effect the response is higher at the high level and when a factor has a negative effect the response is lower at the high level. The higher the absolute value of a coefficient the more important the weight of the corresponding variable.

3.2.2. Statistical and experimental verification of the predictive models. Three basic groups of analysis were used to verify the model significance: (1) coefficient significance $(\alpha=$ 0.05); (2) model consistency (Fisher F-test); and (3) other statistical criteria $\left(R^{2}, R^{2}\right.$ adj, MSE, RMSE, MAPE, DW coefficient, and ANOVA). Only in three cases ( $\beta$-carotene bleaching inhibition, TBARS formation inhibition and oxalic acid) the statistical verification failed in at least one of the groups or subgroups described. In all other cases the models are workable and can be applied in the subsequent prediction and optimisation stages showing a good agreement between the experimental and predicted values which implies that the variation is explained by the independent variables.

All significant models presented high values of $R^{2}$ and $R_{\text {adj }}^{2}$ (Table 2) which indicates the percentage of variability of each response explained by the models. The statistical lack of fit (MSE, RMSE, MAPE, and DW coefficient) used to test the adequacy of the developed models demonstrated that a non-considerable improvement was achieved by the inclusion of the statistically non-significant (ns) parameters (Table 2). In addition the ANOVA results for the regression equations are presented in Tables S2-S5 of the ESI. $\dagger$ The linear and quadratic terms were highly significant $(p<0.01)$. The lack of fit (used to verify the adequacy of the model) was not significant $(p>0.05)$ which indicates that the model fits adequately to the experimental data.

In general the behaviour of the extraction kinetics can be understood by the second-order polynomial models described in eqn (6)-(30). To make more explicit the RSM combinations and visually present the tendencies the effects of irradiation in the kinetics of the extraction process are discussed below in detail.

\subsection{Analysis of the response surfaces}

The combined effects of the ionizing radiation dose and extraction time on the extraction yield and on the extractability of organic acids ellagitannin derivatives and other phenolic compounds (flavonoids and a phenolic acid) from T. lignosa are presented in Fig. 2. On the left-hand side are presented the $3 \mathrm{D}$ response surface plots as a function of the studied independent variables. The grid surface was built using the theoretical values predicted with the second order polynomial of eqn (5). The points $(\bullet)$ represent the experimental results presented in Table 1. The statistical information is illustrated on the right-hand side using two basic graphical criteria depicting the capacity to predict the obtained results (based on $R^{2}$ coefficients) and the residual distribution as a function of each variable. The distribution of residuals is shown always randomly scattered around zero and grouped data and autocorrelations 


\section{A: JOIN ACTION}
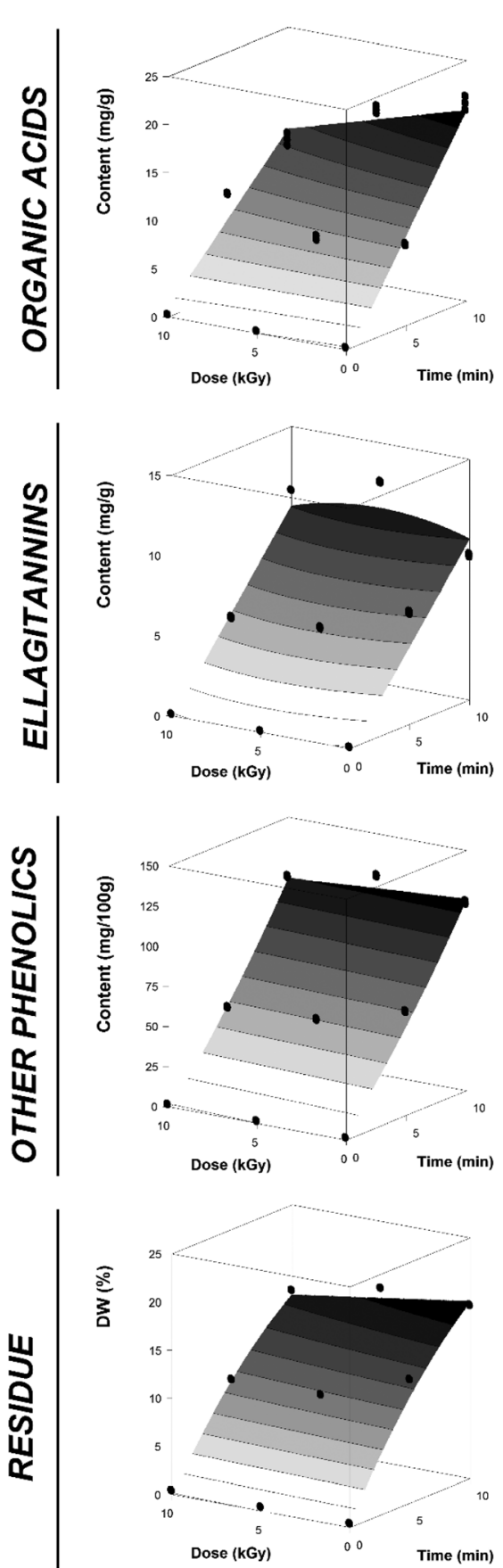

\section{B: STATISTICAL ANALYSIS}
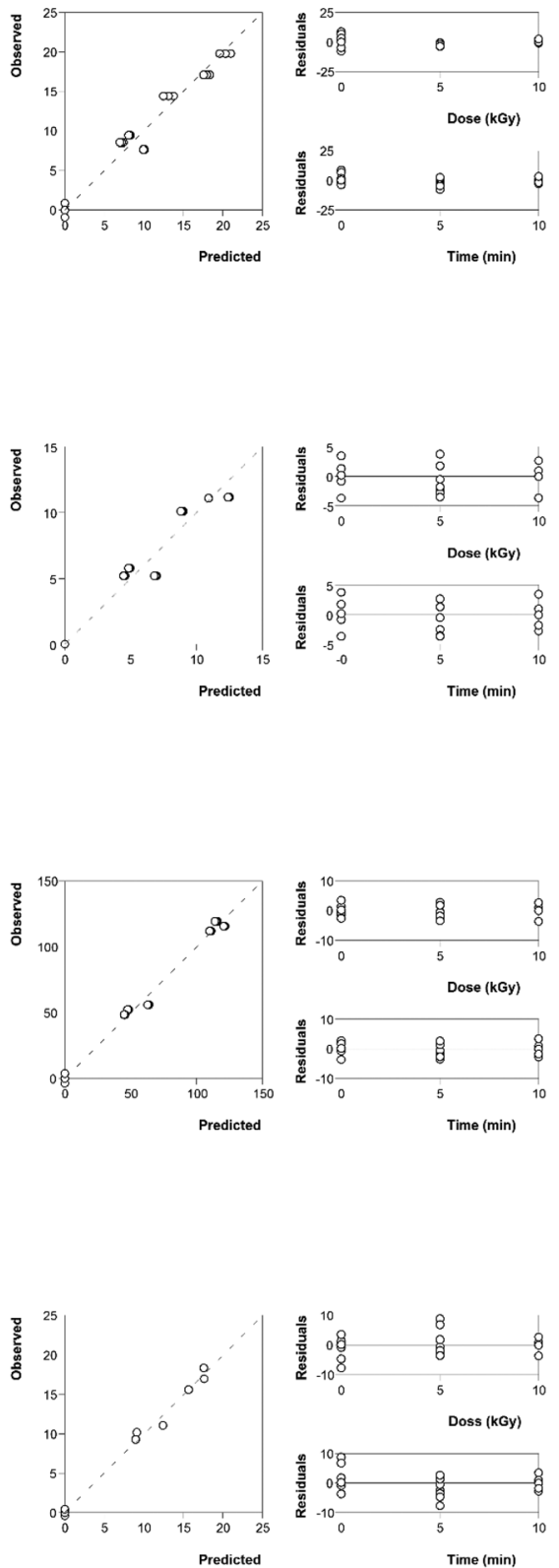

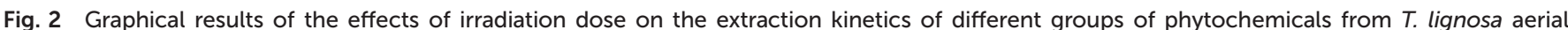

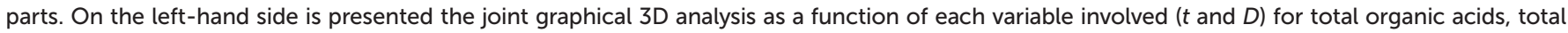

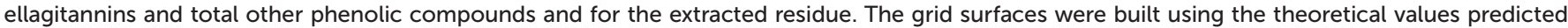

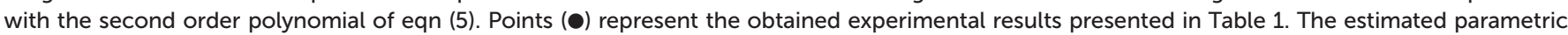

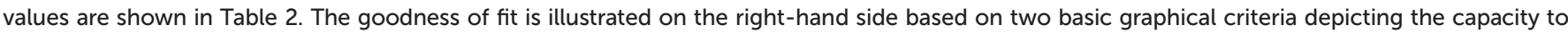
predict the obtained results (based on $R^{2}$ coefficients) and the residual distribution as a function of each variable.

are not observed. This means that these models are workable and can be applied in subsequent prediction stages. It also indicated a good agreement between the experimental and predicted values $\left(R^{2}>0.95\right)$ which implies that the variation can be explained by the independent processing variables. The estimated parametric values are shown in Table 2.

The extraction yield was improved by longer extraction times through a nonlinear interactive manner (Fig. 2 and 
Table 2) whereas the irradiation treatment led to a linear decrease in the amount of the extracted residue (the extraction process efficacy was decreased to $13.28 \%$ by the maximum dose tested; Table 3).

The higher levels of total organic acids were obtained from non-irradiated materials extracted for $10 \mathrm{~min}$ (Fig. 2). The extraction yield of the total of these compounds decreased to $22.16 \%$ by the action of the irradiation treatment (Table 3). A decrease of the total organic acid content was also verified by Fernandes et $a .^{36}$ in dried samples of the wild mushrooms Boletus edulis Bull. and Russula delica Fr. electron-beam irradiated at $10 \mathrm{kGy}$. This phenomenon can be explained by the direct decomposition effect of gamma (or electron-beam) radiation on these organic compounds. Regarding the impact on specific organic acids (Fig. 3) it was observed that the extractability of quinic acid increases with the consequent increase in extraction time and ionizing radiation dose. Due to these nonlinear and linear interactive effects respectively when extracting the plant material irradiated at $10 \mathrm{kGy}$ for $10 \mathrm{~min}$ the maximum value of $3.93 \mathrm{mg}$ of quinic acid per $\mathrm{g}$ of plant material was obtained. Furthermore a negative quadratic effect on the extraction time was also found, i.e. when extracting the non-irradiated plant material ( $0 \mathrm{kGy}$ ) for $10 \mathrm{~min}$ the extraction yield of this compound decreased. On the other hand, the extraction time had a positive quadratic effect on the extracta- bility of succinic acid and interacted negatively with the ionizing radiation dose which means that increasing the dose decreases the yield of this compound (in 39.32\%) in accordance with the trend verified for the total organic acid content. Shikimic acid, the most abundant organic acid in T. lignosa, was not affected by the irradiation dose (Table 3). The preservation of this compound was also verified by Pereira et al. ${ }^{37}$ in Ginkgo biloba L. samples gamma irradiated at doses up to 10 $\mathrm{kGy}$. The results for oxalic acid were not statistically significant $\left(R^{2} \leq 0.69\right)$.

Concerning the group of ellagitannins (manly punicalagin derivatives) it was verified that a linear effect of the extraction time leads to a higher yield of these compounds at $10 \mathrm{~min}$ of extraction. Intermediate ionizing radiation doses promoted the extractability of these added-value compounds. Thus the higher yields ( 12.4 mg per $\mathrm{g}$ P) were achieved with the observations 8, 17 and 26 corresponding to the $5 \mathrm{kGy}$ dose and $10 \mathrm{~min}$ of extraction (Table 1). This effect can also be seen in Fig. 1 which shows a comparison of the HPLC phenolic profile of the extracts obtained from samples non-irradiated ( 0 kGy) and irradiated at $5 \mathrm{kGy}$ processed for $10 \mathrm{~min}$. The $10 \mathrm{kGy}$ dose did not induce significant effects on the total content of ellagitannins (Table 3). In the case of punicalin (Fig. 3) this ellagitannin was degraded with the consequent increase in irradiation dose and a slight negative interaction between both

Table 3 Global variable effect (\%) computed from the developed Box-Behnken model (eqn (5)) presented in Table 2 for each evaluated response. The effect of the variable was linear (L) or non-linear (NL) and in both cases there was or not an interactive effect (I). The arrows represent the effect of increasing $(\uparrow)$ or decreasing $(\downarrow)$ the extraction. The percentage of this effect is presented between brackets

\begin{tabular}{|c|c|c|c|}
\hline \multirow[b]{2}{*}{ Responses } & & \multicolumn{2}{|l|}{ Variable effects } \\
\hline & & Time (\%) & Dose (\%) \\
\hline Extraction yield & Residue & NL-I $\uparrow(100)$ & L-I $\downarrow(13.28)$ \\
\hline \multirow[t]{4}{*}{ Antioxidant activity } & $\mathrm{DPPH}^{\circ}$ scavenging activity & $\mathrm{NL} \uparrow(79.60)$ & $\mathrm{L} \uparrow(20.40)$ \\
\hline & Reducing power & $\mathrm{NL} \uparrow(82.41)$ & $\mathrm{L} \uparrow(17.59)$ \\
\hline & $\beta$-Carotene bleaching inhibition & $\mathrm{NL} \uparrow(100)$ & ns \\
\hline & TBARS formation inhibition & $\mathrm{NL} \uparrow(100)$ & ns \\
\hline \multirow[t]{5}{*}{ Organic acids } & Oxalic acid & $\mathrm{L}-\mathrm{I} \uparrow(100)$ & L-I $\downarrow(30.15)$ \\
\hline & Quinic acid & NL-I $\uparrow(63.59)$ & L-I $\uparrow(36.41)$ \\
\hline & Shikimic acid & $\mathrm{NL} \uparrow(100)$ & ns \\
\hline & Succinic acid & NL-I $\uparrow(100)$ & L-I $\downarrow(39.32)$ \\
\hline & Total & $\mathrm{L}-\mathrm{I} \uparrow(100)$ & $\mathrm{L}-\mathrm{I} \downarrow(22.16)$ \\
\hline \multirow[t]{6}{*}{ Ellagitannin derivatives } & Punicalin & $\mathrm{L}-\mathrm{I} \uparrow(100)$ & NL-I $\downarrow(16.78)$ \\
\hline & Punicalagin (isomer 1) & $\mathrm{L} \uparrow(100)$ & ns \\
\hline & Punicalagin gallate (isomer 1) & $\mathrm{L}-\mathrm{I} \uparrow(78.25)$ & NL-I $\downarrow(21.75)$ \\
\hline & Punicalagin (isomer 2) & $\mathrm{L} \uparrow(100)$ & ns \\
\hline & Punicalagin gallate (isomer 2) & NL-I $\uparrow(56.57)$ & $\mathrm{L}-\mathrm{I} \uparrow(43.43)$ \\
\hline & Total & $\mathrm{L} \uparrow(100)$ & ns \\
\hline \multirow[t]{9}{*}{ Other phenolic compounds } & Luteolin-6- $C$-glucose-8- $C$-glucose & $\mathrm{NL} \uparrow(100)$ & $\mathrm{NL} \downarrow(6.64)$ \\
\hline & 5-O-p-Coumaroylquinic acid & $\mathrm{L}-\mathrm{I} \uparrow(100)$ & $\mathrm{L}-\mathrm{I} \downarrow(35.22)$ \\
\hline & Luteolin-8-C-glucoside & NL-I $\uparrow(77.48)$ & NL-I $\uparrow(22.52)$ \\
\hline & Apigenin-8- $C$-glucoside & $\mathrm{NL} \uparrow(100)$ & $\mathrm{L} \downarrow(7.33)$ \\
\hline & Quercetin-3-O-rutinoside & NL-I $\uparrow(82.15)$ & $\mathrm{L}-\mathrm{I} \uparrow(17.85)$ \\
\hline & Apigenin-6-C-glucoside & $\mathrm{L} \uparrow(100)$ & $\mathrm{L} \downarrow(6.12)$ \\
\hline & Kaempferol-3-O-rutinoside & NL-I $\uparrow(100)$ & L-I $\downarrow(21.56)$ \\
\hline & Luteolin-6-C-hexoside & $\mathrm{NL} \uparrow(100)$ & $\mathrm{L} \downarrow(13.53)$ \\
\hline & Total & $\mathrm{NL} \uparrow(100)$ & $\mathrm{L} \downarrow(6.05)$ \\
\hline
\end{tabular}

ns: no significant effect was found. 


\section{A: ORGANIC ACIDS}
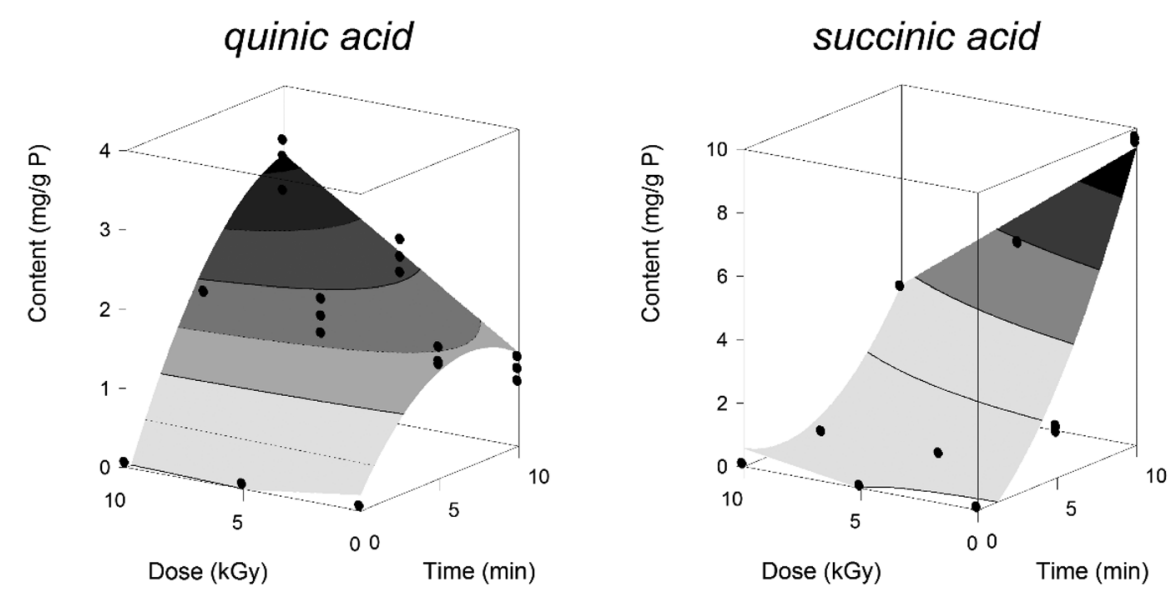

\section{B: ELLAGITANNINS}
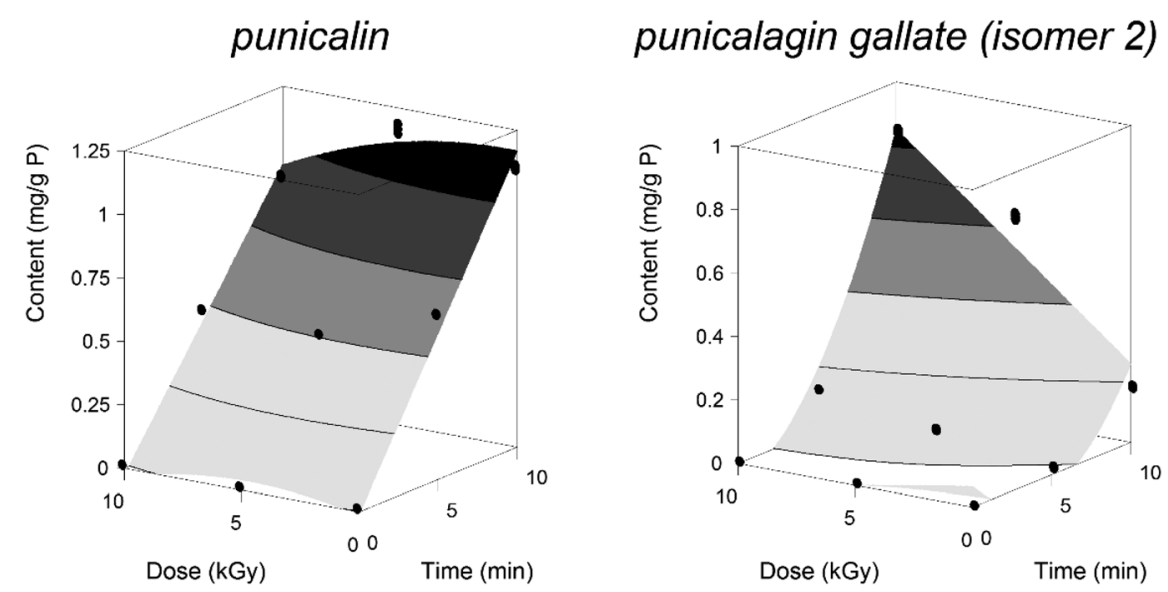

\section{C: OTHER PHENOLICS}
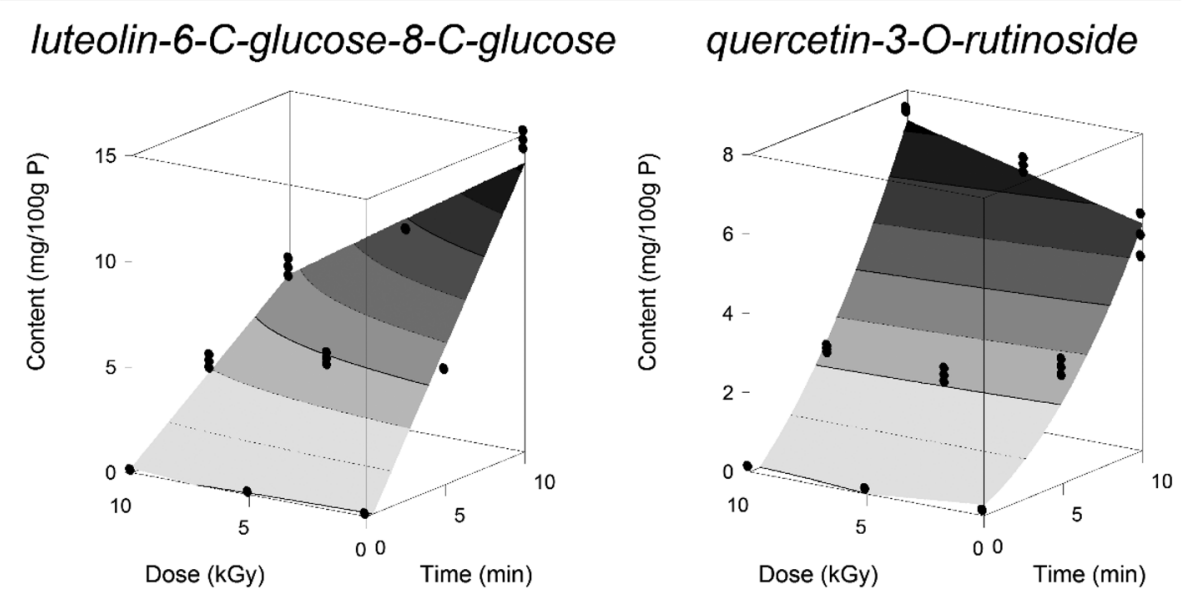

Fig. 3 Graphical results of the effects of irradiation dose on the extraction kinetics of selected phytochemicals from T. lignosa aerial parts. The grid surfaces were built using the theoretical values predicted with the second order polynomial of eqn (5). Points (๑) represent the obtained experimental results presented in Table 1. The estimated parametric values are shown in Table 2. 
independent variables was also observed (Table 2). In contrast, punicalagin gallate (isomer 2) was better extracted from plant material irradiated at higher doses. The $10 \mathrm{kGy}$ dose improved the extraction efficacy of this compound by $43.43 \%$ (Table 3 ) leading to amounts of $0.82 \mathrm{mg}$ per $\mathrm{g}$ P. A positive interaction between both variables was also found for both isomers of punicalagin gallate. As far as we know studies regarding the impact of processing by ionizing radiation on ellagitannin derivatives are very scarce. In addition, it is important to highlight the antioxidant properties of punicalagin and punicalin. According to previous studies these compounds have a strong free-radical (DPPH ABTS and hydroxyl radicals) scavenging capacity ${ }^{38-41}$ that has been attributed to their high degree of hydroxylation. ${ }^{3,42}$

The extraction kinetics of the other phenolic compounds present in the phenolic fraction (one phenolic acid and seven flavonoids) was also affected by the applied treatment. As verified for organic acids and ellagitannins longer extraction times favoured the extraction of the total content of these compounds (Table 2) but a linear decrease of $6.05 \%$ was caused by the irradiation dose (Table 3). Irradiation also decreased the hydrophilic antioxidant responses (which had higher IC $_{50}$ values). Comparable extraction trends were reported by Martins et al. $;^{43}$ longer preparation procedures led to a higher recovery of flavonoids and total phenolic compounds from thyme and oregano (Origanum vulgare L.). In the particular case of luteolin-6-C-glucose-8-C-glucose (Fig. 3 ) its extractability decreases by $6.64 \%$ with the increase of the irradiation dose up to $10 \mathrm{kGy}$. In turn the extractability of luteolin-8- $C$-glucoside and quercetin-3-O-rutinoside was improved by the dose in 22.52 and $17.85 \%$ through nonlinear interactive and linear interactive effects respectively. 5-O-p-coumaroylquinic acid (the only quantified phenolic acid) was greatly affected by the irradiation treatment.

\subsection{Industrial relevance}

Ionizing radiation is the most effective technique for preserving the phytochemical composition and bioactive properties of plant commodities to ensure their hygienic quality and reduce losses associated with insect infestation and microbial contamination. ${ }^{15,17,22,37}$ For the different industrial sectors interested in plant materials (in particular medicinal plants and herbs) the use of suitable preservation/decontamination treatments is critical to obtain high quality raw material. Ionizing radiation has been increasingly used and for this reason it is important to know how the treatment affects the integrity and extractability of different biomolecules. This study provides information little explored so far on the ionizing radiation effects on the extraction/degradation kinetics of high added-value phytochemicals from $T$. lignosa aerial parts. This medicinal plant was selected due to its interesting composition in ellagitannins namely punicalin and punicalagin derivatives (whose levels can reach $221 \mathrm{mg} \mathrm{g}^{-1}$ extract), ${ }^{4}$ bioactive polyphenols with several medical and pharmaceutical applications. $^{5-7}$

\section{Conclusions}

Chromatographic and spectrometric methods were successfully combined with RSM for evaluating the impact of gamma radiation on obtaining ellagitannin-rich extracts from T. lignosa. The extracts were particularly rich in hydrophilic antioxidants (measured by in vitro assays) and the content of different phytochemicals was improved by longer processing times. In general the ellagitannin derivatives $(\sim 90 \%$ of the phenolic fraction) were not significantly affected by the highest irradiation dose. However the group consisting of flavonoids and a phenolic acid and the group of organic acids were negatively affected by irradiation. Therefore, depending on the dose the irradiation treatment (applied for decontamination/quarantine purposes) will preserve the ellagitannins' content or improve their extraction. The obtained functional extracts could be used in the development of functional foods and nutraceuticals. This study also highlights T. lignosa as a source of high added-value molecules, which may be responsible for the therapeutic properties attributed to this plant highly regarded in the Northeastern region of Portugal.

\section{Acknowledgements}

The authors are grateful to the PRODER research project no. 53514 AROMAP for financial support of the work; to the Foundation for Science and Technology (FCT) of Portugal and FEDER under Programme PT2020 for financial support to CIMO (UID/AGR/00690/2013); to FCT/MEC for financial support to REQUIMTE/LAQV (UID/QUI/50006/2013 - POCI/01/ 0145/FERDER/007265); to FCT for the grants attributed to J. Pinela (SFRH/BD/92994/2013; funded by the European Social Fund and MEC through Programa Operacional Capital Humano (POCH)) and L. Barros (SFRH/BPD/107855/2015); to the Xunta de Galicia for financial support to M. A. Prieto.

\section{References}

1 A. Gurib-Fakim, Medicinal plants: Traditions of yesterday and drugs of tomorrow, Mol. Aspects Med., 2006, 27, 1-93.

2 T. Gull, F. Anwar, B. Sultana, M. A. C. Alcayde and W. Nouman, Capparis species: A potential source of bioactives and high-value components: A review, Ind. Crops Prod., 2015, 67, 81-96.

3 J. M. Landete, Ellagitannins ellagic acid and their derived metabolites: A review about source metabolism functions and health, Food Res. Int., 2011, 44, 1150-1160.

4 J. Pinela, L. Barros, M. Dueñas, A. M. Carvalho, C. SantosBuelga and I. C. F. R. Ferreira, Antioxidant activity ascorbic acid phenolic compounds and sugars of wild and commercial Tuberaria lignosa samples: Effects of drying and oral preparation methods, Food Chem., 2012, 135, 1028-1035.

5 L. Yaidikar and S. Thakur, Punicalagin attenuated cerebral ischemia-reperfusion insult via inhibition of proinflam- 
matory cytokines up-regulation of Bcl-2 down-regulation of Bax and caspase-3, Mol. Cell. Biochem., 2015, 402, 141-148.

6 F. Rao, H. Tian, W. Li, H. Hung and F. Sun, Potential role of punicalagin against oxidative stress induced testicular damage, Asian J. Androl., 2016, 18, 627-632.

7 J. Zhong, E. A. Reece and P. Yang, Punicalagin exerts protective effect against high glucose-induced cellular stress and neural tube defects, Biochem. Biophys. Res. Commun., 2015, 467, 179-184.

8 J. Pinela, L. Barros, A. M. Carvalho and I. C. F. R. Ferreira, Influence of the drying method in the antioxidant potential and chemical composition of four shrubby flowering plants from the tribe Genisteae (Fabaceae), Food Chem. Toxicol., 2011, 49, 2983-2989.

9 I. Ihsanullah and A. Rashid, Current activities in food irradiation as a sanitary and phytosanitary treatment in the Asia and the Pacific Region and a comparison with advanced countries, Food Control, 2016, 345-359.

10 UNEP, 2014 Report of the methyl bromide technical options committee, Nairobi, Kenya, 2006.

11 J. Pinela and I. C. F. R. Ferreira, Nonthermal physical technologies to decontaminate and extend the shelf-life of fruits and vegetables: Trends aiming at quality and safety, Crit. Rev. Food Sci. Nutr., 2017, 57, 2095-2111.

12 T. Kausar, K. Akram and J.-H. Kwon, Comparative effects of irradiation fumigation and storage on the free amino acids and sugar contents of green black and oolong teas, Radiat. Phys. Chem., 2013, 86, 96-101.

13 FAO/IAEA/WHO, High-dose irradiation: wholesomeness of food irradiated with doses above $10 \mathrm{kGy}, 1999$.

14 M. N. C. Harder, V. Arthur and P. B. Arthur, Irradiation of foods: Processing technology and effects on nutrients: Effect of ionizing radiation on food components, in Encyclopedia of Food and Health, 2016, pp. 476-481.

15 M. Alothman, R. Bhat and A. A. Karim, Effects of radiation processing on phytochemicals and antioxidants in plant produce, Trends Food Sci. Technol., 2009, 20, 201-212.

16 M. Adamo, D. Capitani, L. Mannina, M. Cristinzio, P. Ragni, A. Tata and R. Coppola, Truffles decontamination treatment by ionizing radiation, Radiat. Phys. Chem., 2004, 71, 167-170.

17 E. Pereira, L. Barros, J. C. M. Barreira, A. M. Carvalho, A. L. Antonio and I. C. F. R. Ferreira, Electron beam and gamma irradiation as feasible conservation technologies for wild Arenaria montana L.: Effects on chemical and antioxidant parameters, Innovative Food Sci. Emerging Technol., 2016, 36, 269-276.

18 E. Pereira, L. Barros, M. Dueñas, A. L. Antonio, C. SantosBuelga and I. C. F. R. Ferreira, Gamma irradiation improves the extractability of phenolic compounds in Ginkgo biloba L, Ind. Crops Prod., 2015, 74, 144-149.

19 J. Pinela, L. Barros, A. L. Antonio, A. Carvalho, M. B. P. P. Oliveira and I. C. F. R. Ferreira, Quality control of gamma irradiated dwarf mallow (Malva neglecta Wallr.) based on color organic acids total phenolics and antioxidant parameters, Molecules, 2016, 21, 467.
20 V. C. Ito, A. Alberti, S. Avila, M. Spoto, A. Nogueira and G. Wosiacki, Effects of gamma radiation on the phenolic compounds and in vitro antioxidant activity of apple pomace flour during storage using multivariate statistical techniques, Innovative Food Sci. Emerging Technol., 2016, 33, 251-259.

21 Â. Fernandes, A. L. Antonio, J. C. M. Barreira, M. B. P. P. Oliveira, A. Martins and I. C. F. R. Ferreira, Effects of gamma irradiation on physical parameters of Lactarius deliciosus, wild edible mushrooms, Postharvest Biol. Technol., 2012, 74, 79-84.

22 J. Pinela, A. L. Antonio, L. Barros, J. C. M. Barreira, A. M. Carvalho, M. B. P. P. Oliveira, C. Santos-Buelga and I. C. F. R. Ferreira, Combined effects of gamma-irradiation and preparation method on antioxidant activity and phenolic composition of Tuberaria lignosa, RSC Adv., 2015, 5, 14756-14767.

23 W. Weibull and S. Sweden, A statistical distribution function of wide applicability, J. Appl. Mech., 1951, 18, 293-297.

24 M. A. Prieto, J. A. Vázquez and M. A. Murado, A critical point: The problems associated with the variety of criteria to quantify the antioxidant capacity, J. Agric. Food Chem., 2014, 62, 5472-5484.

25 C. Pereira, L. Barros, A. M. Carvalho and I. C. F. R. Ferreira, Use of UFLC-PDA for the analysis of organic acids in thirtyfive species of food and medicinal plants, Food Anal. Methods, 2013, 6, 1337-1344.

26 L. Barros, C. Pereira and I. C. F. R. Ferreira, Optimized analysis of organic acids in edible mushrooms from Portugal by ultra fast liquid chromatography and photodiode array detection, Food Anal. Methods, 2013, 6, 309-316.

27 S. M. F. Bessada, J. C. M. Barreira, L. Barros, I. C. F. R. Ferreira and M. B. P. P. Oliveira, Phenolic profile and antioxidant activity of Coleostephus myconis (L.) Rchb.f.: An underexploited and highly disseminated species, Ind. Crops Prod., 2016, 89, 45-51.

28 G. Kemmer and S. Keller, Nonlinear least-squares data fitting in Excel spreadsheets, Nat. Protocols, 2010, 5, 267281.

29 M. A. Murado and M. A. Prieto, Dose-response analysis in the joint action of two effectors. A new approach to simulation identification and modelling of some basic interactions, PLoS One, 2013, 8, e61391.

30 S. Prikler, Advanced Excel for scientific data analysis, ed. R. de Levie, 2nd edn, 2009.

31 P. Shi and C.-L. Tsai, Regression Model Selection: A Residual Likelihood Approach, J. R. Stat. Soc. B (Statistical Methodol.), 2002, 64, 237-252.

32 C. Comuzzi, P. Polese, A. Melchior, R. Portanova and M. Tolazzi, SOLVERSTAT: a new utility for multipurpose analysis. An application to the investigation of dioxygenated $\mathrm{Co}$ (II) complex formation in dimethylsulfoxide solution, Talanta, 2003, 59, 67-80.

33 M. Carocho and I. C. F. R. Ferreira, A review on antioxidants prooxidants and related controversy: Natural and synthetic compounds screening and analysis methodologies 
and future perspectives, Food Chem. Toxicol., 2013, 51, 1525.

34 A. De Lean, P. J. Munson and D. Rodbard, Simultaneous analysis of families of sigmoidal curves: Application to bioassay radioligand assay and physiological dose-response curves, Am. J. Physiol., 1978, 235, E97-102.

35 M. A. Murado and M. A. Prieto, NOEC and LOEC as merely concessive expedients: Two unambiguous alternatives and some criteria to maximize the efficiency of dose-response experimental designs, Sci. Total Environ., 2013, 461-462, 576-586.

36 Â. Fernandes, J. C. M. Barreira, A. L. Antonio, M. B. P. P. Oliveira, A. Martins and I. C. F. R. Ferreira, Feasibility of electron-beam irradiation to preserve wild dried mushrooms: Effects on chemical composition and antioxidant activity, Innovative Food Sci. Emerging Technol., 2014, 22, 158-166.

37 E. Pereira, L. Barros, A. Antonio, A. Bento and I. C. F. R. Ferreira, Analytical methods applied to assess the effects of gamma irradiation on color chemical composition and antioxidant activity of Ginkgo biloba L., Food Anal. Methods, 2015, 8, 154-163.

38 Y. Wang, H. Zhang, H. Liang and Q. Yuan, Purification antioxidant activity and protein-precipitating capacity of punicalin from pomegranate husk, Food Chem., 2013, 138, 437-443.

39 A. P. Kulkarni, S. M. Aradhya and S. Divakar, Isolation and identification of a radical scavenging antioxidant - punicalagin from pith and carpellary membrane of pomegranate fruit, Food Chem., 2004, 87, 551-557.

40 A. Vora, V. Londhe and N. Pandita, Herbosomes enhance the in vivo antioxidant activity and bioavailability of punicalagins from standardized pomegranate extract, J. Funct. Foods, 2015, 12, 540-548.

41 P. Mena, S. Vegara, N. Martí, C. García-Viguera, D. Saura and $\mathrm{M}$. Valero, Changes on indigenous microbiota colour bioactive compounds and antioxidant activity of pasteurised pomegranate juice, Food Chem., 2013, 141, 21222129.

42 J. Moilanen, M. Karonen, P. Tähtinen, R. Jacquet, S. Quideau and J.-P. Salminen, Biological activity of ellagitannins: Effects as anti-oxidants pro-oxidants and metal chelators, Phytochemistry, 2016, 125, 65-72.

43 N. Martins, L. Barros, C. Santos-Buelga, M. Henriques, S. Silva and I. C. F. R. Ferreira, Decoction infusion and hydroalcoholic extract of Origanum vulgare L.: Different performances regarding bioactivity and phenolic compounds, Food Chem., 2014, 158, 73-80. 